\title{
Drugs, Achievements and Educational Systems: Predictive Models for Society and Education through Speculative Data
}

\author{
Ana S. Moura ${ }^{1}$, João Barreiros ${ }^{2}$, M. Natália D. S. Cordeiro ${ }^{1}$ \\ ${ }^{1}$ LAQV-REQUIMTE, Department of Chemistry and Biochemistry, Faculdade de Ciências, \\ Universidade do Porto, Portugal, ${ }^{2}$ Author of Speculative Fiction, Portugal.
}

\begin{abstract}
Higher Education Student burnout is an increasingly educational and social concern. The problem is complex and multilayered, demanding new approaches in predicting hazardous situations that can lead to the demise of the mental and physical well-being of the students. This work proposes a new model that can be used to predict and prevent such educational and/or social scenarios, resourcing to new tools, as the Reductio ad dystopia and speculative data. It departs from recent social quantum-based models and selected speculative literature works while introducing the use of social network theory to add the time variable to the model. The results clearly indicate that speculative and real scenarios can be juxtaposed in such a model, and concludes that a time interval for predicting the occurrence of the problem can be one of its advantages.
\end{abstract}

Keywords: Higher education; Student burnout; Social quantum-based model; Reductio ad dystopia; Predictive social networks; Drug use. 


\section{Introduction}

Higher Education student burnout and the resource to drugs to address it, as well as the anxiety or cognitive demands related to it, are becoming an increasingly social and educational problem (Salmela-Aro \& Read, 2017; Böke et al, 2019). New approaches regarding this, as well as other educational matters, demand that new models be developed to research these problems, propose effective and humane solutions, and, ideally, predict future issues that jeopardize the life and the mental well-being of students. Recently, new models proposing that creative literary works can provide data to research educational and sociological issues have been presented (Moura et al., 2018a; Moura et al., 2019; Moura et $a l ., 2020)$. The models depart from the fact that imagination is a recognized neurocognitive capacity, essential to survival and creative endeavor, something that can be verified as it allows to interact in preventive manners with both real and virtual scenarios (Fuster, 2013).

Speculative fiction, namely science fiction literature, explores hypothetical scenarios regarding not only technological but also sociological situations, especially in the case of dystopias. The models based their departing premise from an already existent educational quantum model within the higher education context (Márquez-Ramos \& Mourelle, 2018) and adjusted it to include data gathered from selected works of speculative literature. Then, by applying a new tool, the Reductio ad dystopia, which is inspired by the mathematical tool of Reductio ad absurdum, the model evaluates the likelihood of a speculative scenario. As in its mathematical counterpart, one departs from a hypothetical hypothesis - an absurd mathematical answer to the problem is replaced here by a hypothetical dystopian future and the probability of such scenario will be evaluated juxtaposing it to reality in the social quantum-based model. Figure 1 illustrates such a situation for a studied case of how the use of Ritalin and similar drugs with the sole purpose to solve bad behavior in small children can be a severe infringement of Human rights (Moura et al., 2020).

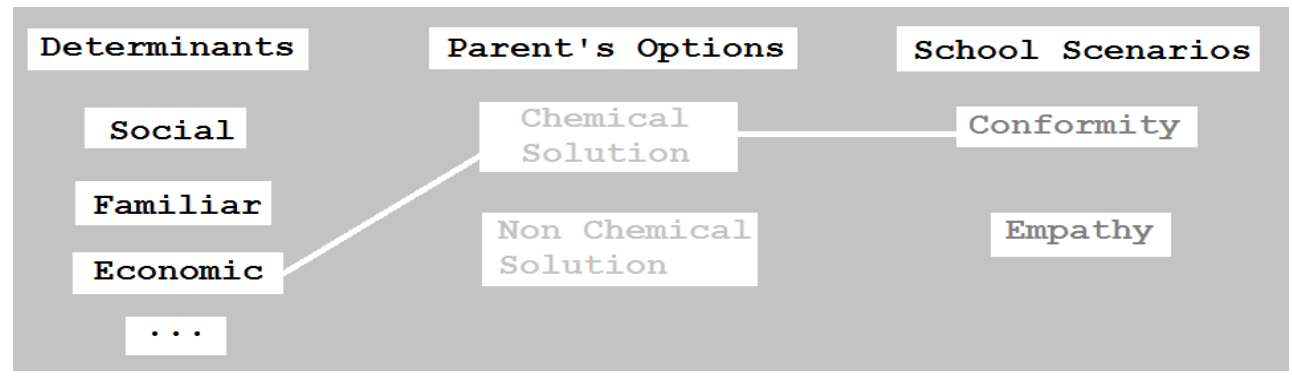

Figure 1. Scheme illustrating the Reductio ad dystopia social quantum model for educational scenarios within the Ritalin context. The first column presents several determinants that may affect the choices of the second column, leading to one of the social scenarios of the third column. By including on the three columns the data from the speculative works, one can apply the Reductio ad dystopia tool. Source: Moura et al., 2020. 
However, the social quantum model lacked the 'time' variable, i.e., the introduction of time as a variable to study the degree of anticipation of the dystopias for a likely future. In this work, we propose to join this model and the Reductio ad dystopia tool to another new model within the use of speculative data for probing sociological situations, and explore the context of Higher Education student burnout and resourcing to drugs as a solution (Moura et al., 2018b). This latter model is inspired by the use of social networks in researching not only biological or medical factors, but also sociological and ethical behavior (Barabási, 2007; Kim et al., 2015; Gentina et al., 2015). To our knowledge, the combined use of these two models in such context is completely new.

\section{Material and Methods}

In this section we present the selected speculative literature works used to gather data, as well as the principles of graph theory used in the dystopian social networks.

\subsection{Selected Literature Works}

From the plethora of published dystopian/science fiction stories, seven were selected: Brave New World, by Aldous Huxley; Beyond Bedlam, by Wyman Guin; Flowers for Algernon, by Daniel Keyes; Fast Times at Fairmont High, by Vernon Vinge; Nexus, by Ramen Naan; Metaquine, by François Rouiller; and The Genius Plague, by David Walton. The order of the selected books reflects their chronological order of publishing.

The selection focused on the use of drugs as a solution to eliminate unhappy, stressful or aggressive states and/or promoting enhancement of neurocapacity. As the model explored time as a variable in predicting the future, an interval of almost one hundred year was chosen. The selected published works belong to different decades within the interval.

\subsection{Extraction of speculative data}

The selected works were read and analyzed. They were given an identity reference to allow the use of graph theory.. In the present context, the graph nodes represent the selected literature works and the edges represent the connections between them. Two different types of connections were established. The idea/concept of two speculative stories was 'kinship' type, i.e., they could be similar or analogous, or the idea/concept of two speculative stories was 'vicinity' type, i.e., they present a logical progression or subsequential nature. For example, Brave New World describes a society where the use of drugs induces normative behavior, eliminating unhappiness and aggressiveness. Therefore, it has a 'kinship' connection with Beyond Bedlam, where drugs are used to eliminate aggressiveness from human beings and achieve world peace. However, Brave New World, as well as Beyond Bedlam, will have a 'vicinity' connection with Fast Time at Fairmont High, which explores a dystopia where students use drugs to increase their mental capacity or become social 
pariahs, as unsuccessful students. The indication of the connection is made using the identity reference numbers. As Brave New World and Beyond Bedlam have been allocated ' 1 ' and ' 2 ' respectively, the indication of their connection is ' 1,2 '. The gathered data, the classification of speculative dystopian concepts and connections, as well as a summary of social and individual options of the selected dystopias, are displayed in Table 1.

Table 1. Summary of selected speculative works regarding mental enhancement and/or socioeducational conformity through imposed social or exogeneous means.

\begin{tabular}{|c|c|c|c|c|c|c|}
\hline $\begin{array}{l}\text { Identity } \\
\text { Ref. }^{1}\end{array}$ & Story & $\begin{array}{l}\text { Decade } \\
\text { / Year }\end{array}$ & Social Scenarios $^{2}$ & $\begin{array}{c}\text { Individual } \\
\text { Consequences }^{3}\end{array}$ & $\begin{array}{l}\text { Concept } \\
\text { type } \\
\text { Kinship }^{4}\end{array}$ & $\begin{array}{c}\text { Concept } \\
\text { type } \\
\text { Vicinity }\end{array}$ \\
\hline 1 & $\begin{array}{l}\text { Brave New } \\
\text { World }\end{array}$ & $\begin{array}{l}30 \mathrm{~s} / \\
1932\end{array}$ & Conformity || Exhile & $\begin{array}{c}\text { Social acceptance } \| \\
\text { Freedom of thought }\end{array}$ & 1,$2 ; 1,5$ & 1,$6 ; 1,4$ \\
\hline 2 & $\begin{array}{l}\text { Beyond } \\
\text { Bedlam }\end{array}$ & $\begin{array}{l}50 \mathrm{~s} / \\
1951\end{array}$ & $\begin{array}{l}\text { Drug acceptance } \| \\
\text { Freedom of thought }\end{array}$ & $\begin{array}{l}\text { Schizrophenia \| } \\
\text { Aggressiveness }\end{array}$ & 2,$1 ; 2,5$ & 2,$4 ; 2,6$ \\
\hline 3 & $\begin{array}{l}\text { Flowers for } \\
\text { Algernon }\end{array}$ & $\begin{array}{l}50 \mathrm{~s} / \\
1959\end{array}$ & $\begin{array}{c}\text { Cognitive impairment } \\
\text { |l Cognitive } \\
\text { enhancement }\end{array}$ & $\begin{array}{l}\text { (Blissful) Ignorance } \\
\text { || Existential stress }\end{array}$ & -- & $\begin{array}{c}3,4 ; 3,6 \\
3,7\end{array}$ \\
\hline 4 & $\begin{array}{l}\text { Fast times } \\
\text { at Fairmont } \\
\text { High }\end{array}$ & $\begin{array}{l}00 \mathrm{~s} / \\
2001\end{array}$ & $\begin{array}{c}\text { Social status \| Social } \\
\text { pariah }\end{array}$ & $\begin{array}{l}\text { Drug addition } \| \\
\text { Health }\end{array}$ & 4,5 & $\begin{array}{l}4,1 ; 4,2 \\
4,3 ; 4,6\end{array}$ \\
\hline 5 & Nexus & $\begin{array}{l}10 \mathrm{~s} / \\
2012\end{array}$ & $\begin{array}{c}\text { Mind connection } \| \\
\text { Individual } \\
\text { preservation }\end{array}$ & $\begin{array}{c}\text { Integration } \| \text { Social } \\
\text { pariah }\end{array}$ & $\begin{array}{l}5,1 ; 5,2 \\
5,4 ; 5,6\end{array}$ & 5,7 \\
\hline 6 & Metaquine & $\begin{array}{l}10 \mathrm{~s} / \\
2016\end{array}$ & $\begin{array}{c}\text { Higher brain } \\
\text { performance } \| \\
\text { Personality integrity }\end{array}$ & $\begin{array}{c}\text { Cyberaddition \| } \\
\text { Educational Outcast }\end{array}$ & 6,5 & $\begin{array}{l}6,1 ; 6,2 \\
6,3 ; 6,4 \\
\quad 6,7\end{array}$ \\
\hline 7 & $\begin{array}{l}\text { The Genius } \\
\text { Plague }\end{array}$ & $\begin{array}{l}10 \mathrm{~s} / \\
2017\end{array}$ & $\begin{array}{l}\text { Increased abilities \| } \\
\text { Individual freedoom }\end{array}$ & $\begin{array}{l}\text { Social disruption \| } \\
\text { Maintenance of } \\
\text { social paradigms }\end{array}$ & -- & 7,$5 ; 7,6$ \\
\hline
\end{tabular}

\footnotetext{
${ }^{1}$ According to chronological publication; ${ }^{2}$ Scenario 1 versus scenario $2 ;{ }^{3}$ Consequence of choosing scenario 1 versus consequences of choosing scenario $2 ;{ }^{4}$ Connection through similar concept between two identity references; ${ }^{5}$ Connection through subsequent concept between two identity references.
}

\section{Social quantum-based model and occurrence prediction}

In this section we explore how the speculative data predicts the present state of affairs and the time anticipation it could have provided to predict and prevent the problem.

\subsection{Social quantum-based model for Higher Education Student burnout}

From the selected speculative works, two major individual and social scenarios were applied to the social quantum-based model proposed by Moura et al. (Moura et a.l, 2018a; 
Moura et al., 2020). The model with the speculative data is illustrated in Figure 2, and presents a well juxtaposed parallelism with contemporary Higher Education student burnout context. Therefore, the Reductio ad dystopia indicates the likelihood of these scenarios being matched with reality.

Determinants

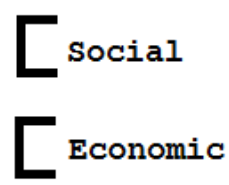

student's options

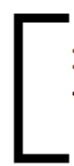

Drug use to cope

with workload and

stress

Not using drug to

cope with workload

and stress
Social Consequences

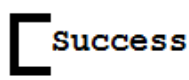

Eailure

Figure 2. Social quantum-based model using the more recurring scenarios of the selected dystopian and science fiction published works.

\subsection{Time prediction with graph theory and visualization}

Using the connections presented in Table 1, three types of predictive social networks were developed through graph theory and visualization. In Figure 3, the layers regarding 'kinship' (layer 1) and 'vicinity' (layer 2) connection types are displayed in graph a) and b) respectively. In layer 1, regarding the 'kinship' type connections, there is a dominance of the 'neurocapacity enhancement through drug use' concept, being the prevalence of connections met at the node representing the Nexus story. The Nexus dystopia approaches the hypothetical student choices through the social imposition of connecting minds while eliminating individuality. However, when you consider the 'vicinity' type connection, layer 2 , the subsequential ideas regarding emotional inhibition or control for educational achievement gain eminence, as noticed by the multiple connections with Metaquine. This is a story where the use of drugs to enhance neurocapacity while producing apathy and conformity in the students is normative.

The third graph visualization allows perceiving how the dystopian scenarios reinforced themselves through time until meeting the contemporary state of affairs. Allocating a color to a specific decade, and departing from 1931 to the final selected narrative, published in 2017, one can see in Figure 4, the emphasis met by the scenario of Fast Times in Fairmont High, which connects either through 'kinship' or 'vicinity' most of the nodes. In this story, either the student is able to be successful in their studies or will meet a future of social exclusion. The high demand and pressure of the workload force many students to resource to drugs to increase their mental capacity and memory, at the risk of health consequences. 


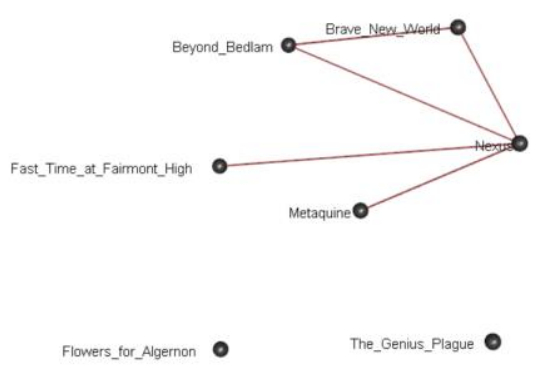

(a)

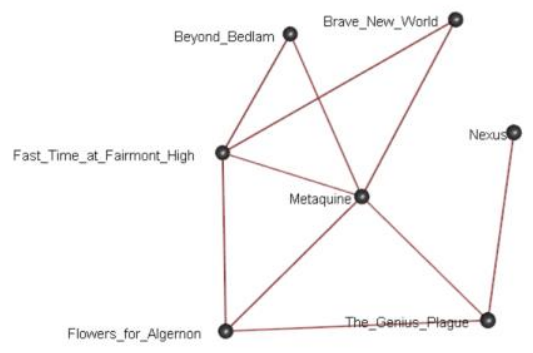

(b)

Figure 3. (a) Graph visualization of the connections between speculative literary sources regarding similar concepts or ideas - Layer 1. Each node represents a speculative work and the connections indicate that the nodes share similar concepts or ideas. (b) Graph visualization of the connections between speculative literary sources regarding subsequent or ensuing concepts or ideas - Layer 2. Each node represents a speculative work and the connections indicate that the nodes share subsequent or ensuing concepts or ideas. Original data and graph.

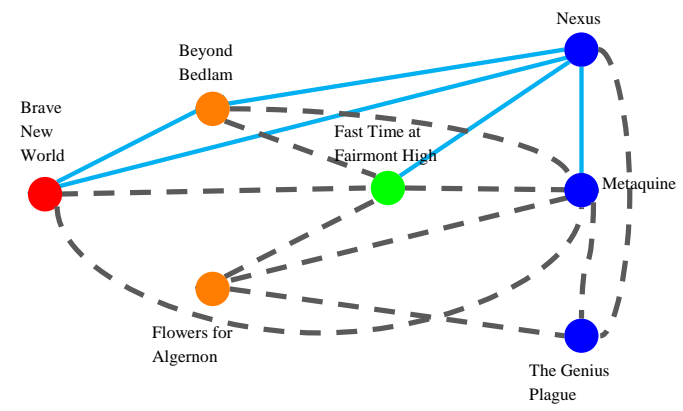

Figure 4. Graph visualization of Layers 1 and 2 per decade (Red, 1930s; orange, 1950s; green, 2000s; blue, 2010s). The dashed line indicates a Layer 2 type of connection (subsequential concept) and the continuum line indicates a Layer 1 type of connection (similar concept). Original data and graph.

It is noteworthy that the publication of Fast Times at Fairmont High is, on average, seventy and fifty years apart from the preceding dystopias but only ten to fifteen years apart from the more contemporary stories. These more recent stories include cyberaddiction and online context in many occasions, as well as the present-day pressure on students that leads to burnout and the resource to drug use to keep up with both the workload and the stress of educational situations. As such, the use of these models could help prevent such real-life scenarios by exploring Reductio ad dystopia juxtaposition of initial cases versus the time period when the speculative data begins to present a 'focal' node, as was the case of Fast Times at Fairmont High. 


\section{Conclusion and Future Perspectives}

Higher Education faces many challenges, the least of them not being the fact that an increasing number of students face burnout during their academic path. Moreover, the options many students chose to deal with such a possibility may be as damaging as the burnout itself. The damage this and other social situations provoke, as well as the need to evaluate solutions that avoid future or new grievances needs to be explored by new methodological approaches. The use of Reductio ad dystopia models with time prediction through social networks can be a useful tool to predict not only these scenarios but the likelihood of 'when' they may become a significant problem. It would also allow us to explore solution scenarios as well, and prevent the loss of the overall well-being of many students.

\section{Acknowledgments}

This work had the financial support of Fundação para a Ciência e a Tecnologia (FCT/MEC) through national funds (UIDB/50006/2020 grant and funding into framework of Norma Transitória - DL 57/2016/CP1346/0019). Ana S. Moura further acknowledges contract IF CEECIND/03631/2017. The authors also want to thank the invaluable help of Patrícia C. T. Gonçalves in the development of the graph models.

\section{References}

Barabási, A.-L. (2007) Network Medicine — From Obesity to the "Diseasome." N. Engl. J. Med. 357, 404-407. doi: 10.1056/NEJMe078114

Böke, N. B., Mills, D. J., Mettler, J., Heath, N. L. (2019). Stress and Coping Patterns of University Students. J. Coll. St. Dev., 60 (1) 85-103 DOI: 10.1353/csd.2019.0005

Fuster, J.M. (2013) The Neuroscience of Freedom and Creativity: Our Predictive Brain. Cambridge University Press

Gentina, E., Rose, G.M., Vitell, S.J. (2015) Ethics During Adolescence: A Social Networks Perspective. J. Bus. Ethics 138 (1) 185-197. doi: 10.1007/s10551-015-2577-5

Guin, W. (1951). Beyond Bedlam (novella). Galaxy Magazine, vol. 2, nº 5, 3-71

Huxley, A. (1932) Brave New World. Chatto \& Windus

Keys, D. (1959) Flowers for Algernon (short story). The Magazine of Fantasy \& Science Fiction, vol. 16, n' 4, 5-31

Kim, D.A., Hwong, A.R., Stafford, D., Hughes, D.A., O’Malley, A.J., Fowler, J.H., Christakis, N.A. (2015) Social network targeting to maximise population behaviour change: a cluster randomised controlled trial. Lancet. 386, 145-153. doi: 10.1016/S0140-6736(15)60095-2 
Márquez-Ramos, L., Mourelle, E. (2018). On the relationship between society and higher education: what path should we take? Distance Education, 39 (1) 19-36. doi: 10.1080/01587919.2018.1436401

Moura, A. S., Seixas, J., Cordeiro, M. N. D. S., Barreiros, J. (2018a). Educational Superavit: Human Rights versus Education Policies. Oral Presentation on the 2nd International Conference on Pathologies and Dysfunctions of Democracy in Media Context, Covilhã, Portugal, November $12^{\text {th }}-14^{\text {th }} 2018$.

Moura, A. S., Seixas, J., Cordeiro, M. N. D. S., Barreiros, J. (2018b). The Right to Be Human: Enhanced Drug Induced Neuracapacity and the Impending Arrival of Real-life 'exomental' Dystopias. Oral Presentation on the 2nd International Conference on Pathologies and Dysfunctions of Democracy in Media Context, Covilhã, Portugal, November $12^{\text {th }}-14^{\text {th }} 2018$.

Moura, A. S., Seixas, J., Cordeiro, M. N. D. S., Barreiros, J. (2019). 'La Casa de Papel' versus School Systems: Computatinal/Quantum Chemistry Models, Educational Hazards and the Elusive Nature of Creativity. Invited Lecture to the 2nd IViMACC $-2^{\text {nd }}$ International Vigo Meeting on Advanced Computational Chemistry, Vigo, Spain, June $6^{\text {th }}-7^{\text {th }} 2019$.

Moura, A. S., Seixas, J., Cordeiro, M. N. D. S., Barreiros, J. (2020). Educational Superavit: Human Rights versus Education Policies. In J. Correia, A. Gradim, \& R. Morais (Eds.), Pathologies and Dysfunctions of Democracy in Media Context, volume 2 (pp 159-172). LabCom Books, Portugal.

Naan, R. (2012) Nexus \#1. Angry Robot

Rouiller, F. (2016). Metaquine T.01: Indications. Atalante

Salmela-Aro, K., Read, S. (2017). Study Engagement and Burnout Profiles among Finnish Higher Education Students. Burnout Research, 7, 21-28. doi: 10.1016/j.burn.2017.11.001.

Vinge, V. (2001). Fast Times at Fairmont High. In The Collected Stories of Vernor Vinge. Tor Books

Walton, D. (2017) The Genius Plague. Amherst, NY: Pyr, Prometheus Books 